\title{
Expression analysis of genes and pathways associated with liver metastases of the uveal melanoma
}

Yuanyuan Zhang ${ }^{1}$, Yong Yang ${ }^{2}$, Lei Chen ${ }^{3^{*}}$ and Jianhong Zhang ${ }^{1^{*}}$

\begin{abstract}
Background: Uveal melanoma is an aggressive cancer which has a high percentage metastasizing to the liver, with a worse prognosis. Identification of patients at high risk of metastases may provide information for early detection of metastases and treatment.

Methods: Expression profiling of ocular tumor tissues from 46 liver metastatic uveal melanoma samples and 45 non-metastatic uveal melanoma samples were got from GEO database. Bioinformatic analyses such as the Gene Oncology and Kyoto Encyclopedia of Genes and Genomes were used to identify genes and pathways specifically associated with liver metastases of the uveal melanoma.

Results: A total of 1138 probes were differentially expressed in two group samples. All differential gene interactions in the Signal-Net were analyzed. Of them, 768 probes were up-regulated and 370 down-regulated. They mainly participated in $125 \mathrm{GO}$ terms and 16 pathways. Of the genes differentially expressed between two group cancers, HTR2B, CHL1, the ZNF family, YWHAZ and FYN were the most significantly altered.

Conclusions: Bioinformatics may help excavate and analyze large amounts of data in microarrays by means of rigorous experimental planning, scientific statistical analysis and collection of complete data about liver metastases of uveal melanoma patients. In the present study, a novel differential gene expression pattern was constructed and advanced study will provide new targets for diagnosis and mechanism of uveal melanoma liver metastases.
\end{abstract}

Keywords: Uveal melanoma, Liver metastases, Gene expression, GO analysis, Pathway analysis

\section{Background}

Uveal melanoma is the most common primary intracellular tumor in adults with an estimated 5-year survival rate of $50 \%-70 \%$ [1]. About $50 \%$ of patients develop metastases within a median of 36 months, mostly to the liver, with a median survival of 6 months after metastases [2]. It seems important to identify high-risk patients at the time of the initial diagnosis for early detection and treatment of metastatic disease or for the administration of adjuvant therapy. Several clinical and histopathological features have been correlated with survival, including patient age $(>60)$, anterior location of the tumor,

\footnotetext{
*Correspondence: leichen51@hotmail.com; zhangjh_0312@aliyun.com

${ }^{3}$ Department of Ophthalmology, The First Hospital of China Medical

University, Shenyang 110001, China

'Department of Ophthalmology, The branch of the first people's hospital of Shanghai, Shanghai 200081, China

Full list of author information is available at the end of the article
}

tumor cell histology, largest diameter of the tumor, mitotic activity, and chromosome 3 monosomy. The most frequent chromosomal imbalances in uveal melanoma are loss of chromosome 3 and gains of $8 \mathrm{q}$ and $6 \mathrm{p}$ [3].

Despite the improvements in diagnosis and the development of more effective local therapies for primary tumors, the rate of metastatic death remains unchanged. Unfortunately, once uveal melanoma has spread to distant organs, the disease is largely resistant to currently available therapies [4]. Nowadays, many new prognostic factors such as Cytological Features, Standard Karyotyping, Fluorescence in situ Hybridization, Centromeric Probes, Single Nucleotide Polymorphism and Gene Expression Profiling were investigated. Following the technique advance and lower expense of gene expression microarray, it has become a useful tool for studying the development and progression of tumors owing to its high throughout, new

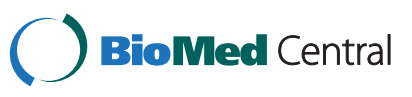


genes which may affect metastases of uveal melanoma could be found.

Several gene expression profiling studies have identified two molecular classes strongly associated with metastatic risk [5-7]. Hepatocyte growth factor/scatter factor (HGF) [8-10], Insulin-like growth factor [11] and Stem cell factor [12-14] receptors have been involved in metastatic progression of uveal melanoma. In addition, the chemokine receptor CXCR4 was recently related to liver homing of human uveal melanoma metastatic cells $[15,16]$. However, little is known about the core genes and their potential mechanisms in liver metastases. The present study made use of bioinformatics method to analyze the data obtained from two public available datasets in combination with the clinical data about metastases of uveal melanoma patients in attempt to investigate the liver metastases-related genes. The different gene ontology and pathways would indicate the most important mechanisms and candidate genes in the process of liver metastases, and helpful in working out more specific and individualized target treatment regimens according to genetic characteristics of individual patients.

\section{Methods}

Tissue samples and clinical data

Tissue samples were obtained from two datasets in total 92 uveal melanomas after enucleation surgery upon approval of the institutional bioethics board. The patients in the two datasets were composed of 63 and 29 samples, respectively $[17,18]$. All the samples were performed on Affymetrix Human Genome U133 Plus 2.0 Array. Both of two data series were accessible at NCBI GEO database, accession GSE22138 and GSE27831. Clinical, pathological, and molecular features of the tumors are presented in Table 1.

\section{Significant differential gene analysis}

All 92 tumors in two datasets were pooled and reanalyzed on Affymetrix Expression Console Software (Version 1.1). MAS5 was used to normalize the original data. One sample was removed after the normalized data filtered with Pearson's Correlation (Additional file 1: Figure S1), and the remaining 91 samples were renormalized. Genes were standardized and interpreted functionally before comparison. Using $t$-test, SAM or RVM mode and the tumors with no metastases as the control group, the $\mathrm{P}$ value and the fold change were calculated for each differentially expressed gene. With a threshold of $\mathrm{P}$ value $<0.05$ or FDR value $<0.05$ and fold change $>=1.5$, related genes were picked out and the venn diagram was showed in Additional file 2: Figure S2. Based on our sample size and previous study [19], $t$-test result was chose for further analyze. Unsupervised hierarchical clustering was performed with Cluster using Pearson's correlation distance
Table 1 Clinicopathologic characteristics of uveal melanoma patients

\begin{tabular}{|c|c|c|}
\hline Characteristic & $\begin{array}{l}\begin{array}{l}\text { Non-metastatic } \\
\text { patients }(n=45)\end{array} \\
\end{array}$ & $\begin{array}{l}\text { Liver metastatic } \\
\text { patients }(n=46)\end{array}$ \\
\hline Mean age, years & $60.96 \pm 14.4$ & $63.17 \pm 10.21$ \\
\hline $\begin{array}{l}\text { Mean primary tumor thickness } \\
(\mathrm{mm})\end{array}$ & $10.13 \pm 2.97$ & $11.45 \pm 2.76$ \\
\hline $\begin{array}{l}\text { Mean tumor largest diameter } \\
(\mathrm{mm})\end{array}$ & $14.64 \pm 4.14$ & $15.08 \pm 4.01$ \\
\hline \multicolumn{3}{|l|}{ Gender, No. of patients } \\
\hline Male & 27 & 29 \\
\hline Female & 18 & 17 \\
\hline \multicolumn{3}{|l|}{ Location of tumor } \\
\hline Anterior & 3 & 4 \\
\hline On equator & 29 & 27 \\
\hline Posterior & 6 & 13 \\
\hline All & 0 & 1 \\
\hline NA & 7 & 1 \\
\hline \multicolumn{3}{|l|}{ Histopathologic cell type } \\
\hline Epithelioid & 9 & 18 \\
\hline Spindle & 8 & 18 \\
\hline Mixed & 16 & 9 \\
\hline NA & 12 & 1 \\
\hline \multicolumn{3}{|l|}{ Extrascleral extension } \\
\hline No & 31 & 31 \\
\hline Yes & 10 & 9 \\
\hline NA & 4 & 6 \\
\hline \multicolumn{3}{|l|}{ Chr 3} \\
\hline Monosomy & 17 & 31 \\
\hline Disomy & 24 & 6 \\
\hline Partial monosomy & 2 & 3 \\
\hline NA & 2 & 6 \\
\hline
\end{tabular}

Clinicopathologic characteristics of uveal melanoma patients got from the published article and each GSM information. NA, not available.

metric and average linkage followed by visualization in Treeview [20].

\section{Gene ontology (GO) analysis}

Based on Gene Ontology Database (http://www.geneontology. org/), the significant level of GOs of the liver metastasesrelated differentially expressed genes was analyzed by two-side Fisher's exact test and $\chi^{2}$ test using DAVID (http://david.abcc.ncifcrf.gov/home.jsp) analysis [21]. The differential expression genes were analyzed independently according to up- and down-regulation of these genes. We computed P-values for all the differential expression genes in all GO categories, and the threshold of significance was defined as $\mathrm{P}$-value $<0.05$. 


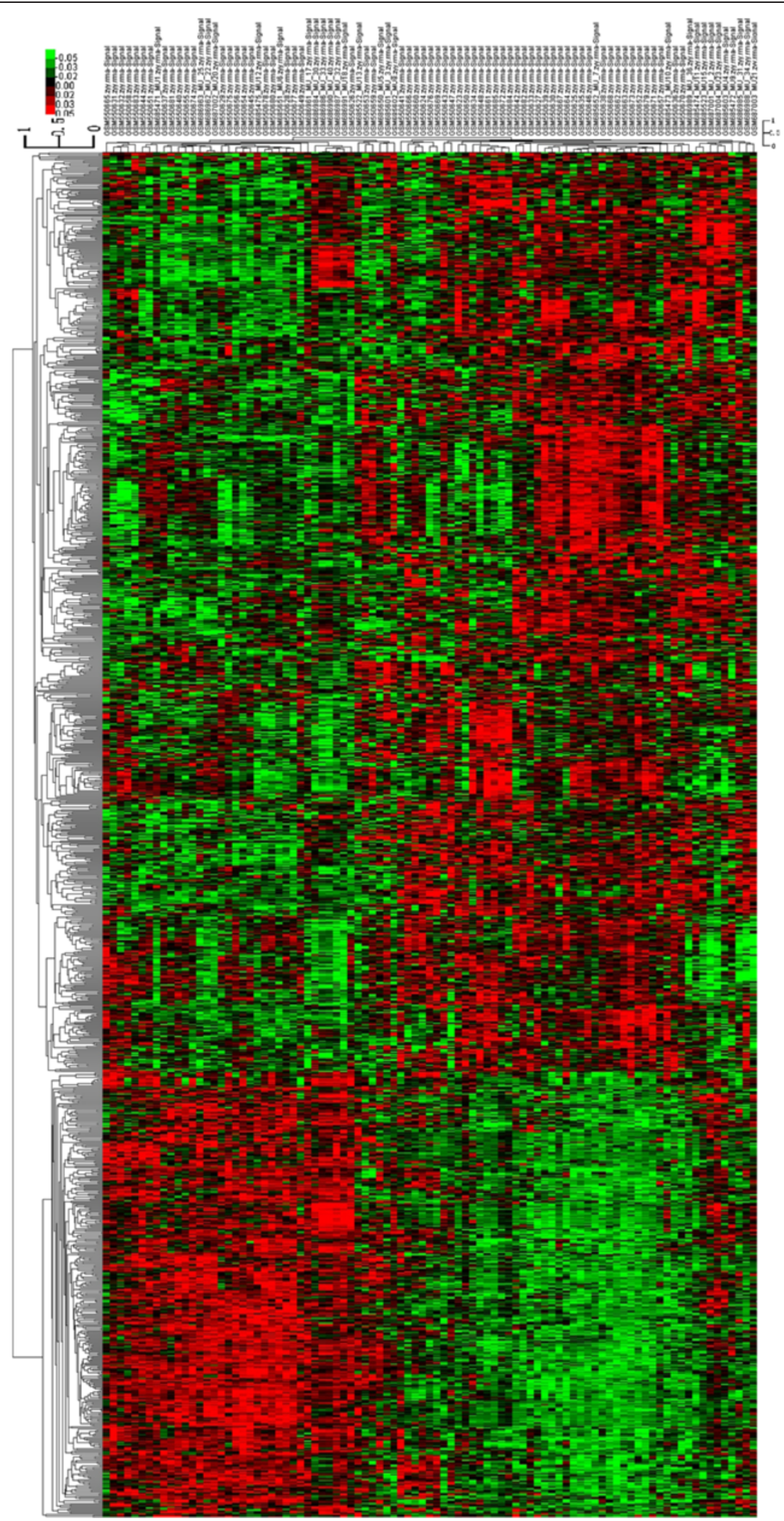

Figure 1 (See legend on next page.) 
(See figure on previous page.)

Figure 1 Unsupervised classification of uveal melanoma samples based on gene expression profiling. Classification of 91 uveal melanoma samples using the 1138-probe sets identified as differentially expressed between the 46 liver metastatic samples and the 45 non-metastatic samples. Expression data are depicted as a data matrix where each row represents a gene and each column represents a sample. Expression levels are depicted according to the color scale shown at the top. Red and green indicate expression levels, respectively, above and below the median. The magnitude of deviation from the median is represented by the color saturation.

\section{Pathway analysis}

Based on KEGG (http://www.genome.jp/kegg/) database, the significant level of pathways of the liver metastasesrelated differentially expressed genes was analyzed by Pathway-Express [22,23]. Significant differences from the expected were calculated with a two-sided binomial distribution. The numbers of genes corresponding to each pathway category among the differentially expressed genes was tallied and compared with the number of genes expected for each pathway category based on their representation on the Affymetrix Human Genome U133 plus 2.0 array. All signaling pathways were analyzed for the significance level, using gamma $\mathrm{P}<0.05$ as the threshold.

Table 2 Most obviously dysregulated genes sorted by $P$ value in liver metastatic uveal melanoma compare to non-metastatic tumors

\begin{tabular}{|c|c|c|c|c|}
\hline $\begin{array}{c}\text { Gene } \\
\text { symbol }\end{array}$ & $P$ value & $\begin{array}{c}\text { Mean of } \\
\text { intensities: } \\
\text { no metastasis }\end{array}$ & $\begin{array}{c}\text { Mean of } \\
\text { intensities: } \\
\text { metastasis }\end{array}$ & $\begin{array}{c}\text { Fold } \\
\text { change }\end{array}$ \\
\hline$\overline{\text { NEURL1B }}$ & $1.67 \times 10^{-9}$ & 51.47 & 88.42 & 1.72 \\
\hline EXT1 & $2.82 \times 10^{-9}$ & 203.15 & 362.35 & 1.78 \\
\hline DERL 1 & $4.89 \times 10^{-9}$ & 178.31 & 412.54 & 2.31 \\
\hline GALNTL4 & $1.22 \times 10^{-8}$ & 57.44 & 128.49 & 2.24 \\
\hline MR1 & $1.41 \times 10^{-8}$ & 60.08 & 98.74 & 1.64 \\
\hline DDX39 & $3.31 \times 10^{-8}$ & 347.31 & 556.46 & 1.60 \\
\hline HTR2B & $3.49 \times 10^{-8}$ & 41.04 & 574.49 & 14.00 \\
\hline RAB2A & $5.29 \times 10^{-8}$ & 363.13 & 741.99 & 2.04 \\
\hline C10orf26 & $6.68 \times 10^{-8}$ & 376.40 & 569.30 & 1.51 \\
\hline GJC1 & $7.39 \times 10^{-8}$ & 25.95 & 75.05 & 2.89 \\
\hline $\mathrm{CHL} 1$ & $8.99 \times 10^{-8}$ & 80.84 & 17.12 & 0.21 \\
\hline ZNF33B & $2.17 \times 10^{-8}$ & 41.91 & 21.24 & 0.51 \\
\hline OVOS2 & $2.44 \times 10^{-8}$ & 857.96 & 185.87 & 0.22 \\
\hline EIF1B & $3.35 \times 10^{-7}$ & 1008.84 & 567.87 & 0.56 \\
\hline PHLDA1 & $5.22 \times 10^{-7}$ & 370.24 & 134.93 & 0.36 \\
\hline PLSCR4 & $5.34 \times 10^{-7}$ & 114.83 & 53.41 & 0.47 \\
\hline MEGF10 & $8.38 \times 10^{-7}$ & 165.39 & 26.05 & 0.16 \\
\hline ZNF415 & $1.19 \times 10^{-6}$ & 37.03 & 13.91 & 0.38 \\
\hline ZNF667 & $1.25 \times 10^{-6}$ & 34.08 & 16.02 & 0.47 \\
\hline MEGF10 & $1.66 \times 10^{-6}$ & 22.24 & 10.21 & 0.46 \\
\hline
\end{tabular}

Most obviously dysregulated genes sorted by $\mathrm{p}$ value in liver metastatic uveal melanoma $(n=45)$ vs. non-metastatic tumors $(n=46)$.

\section{Signal-net analysis}

Using java that allows users to build and analyze molecular networks, network maps were constructed. For instance, if there is confirmative evidence that two genes interact with each other, an interaction edge is assigned between the two genes. The considered evidence is the source of the interaction database from KEGG. Networks are stored and presented as graphs, where nodes are mainly genes (protein, compound, etc.) and edges represent relation types between the nodes, e.g. activation or phosphorylation. The graph nature of Networks raised our interest to investigate them with powerful tools implemented in $\mathrm{R}$.

\section{Data analysis}

Numerical data were presented as means and standard deviation $( \pm$ SD). Differences between means were analyzed using Student's $t$ test. All statistical analyses were performed using SPSS11.0 software (Chicago, IL).

\section{Results}

Clinical characteristics of the two group samples

Comparing with the non-metastases uveal melanoma samples, the liver metastases group has no differences

Table 3 Most obviously dysregulated genes with fold change absolute value $>\mathbf{3}$ in liver Metastatic Uveal Melanoma compare to non-metastatic tumors

\begin{tabular}{ccccc}
\hline $\begin{array}{c}\text { Gene } \\
\text { symbol }\end{array}$ & P value & $\begin{array}{c}\text { Mean of } \\
\text { intensities: } \\
\text { no metastasis }\end{array}$ & $\begin{array}{c}\text { Mean of } \\
\text { intensities: } \\
\text { metastasis }\end{array}$ & $\begin{array}{c}\text { Fold } \\
\text { change }\end{array}$ \\
\hline HTR2B & $3.49 \times 10^{-8}$ & 5.36 & 9.17 & 14.00 \\
PPM1K & $2.96 \times 10^{-6}$ & 7.67 & 9.39 & 3.30 \\
SSX4 & $1.03 \times 10^{-4}$ & 5.65 & 7.28 & 3.09 \\
PTGER4 & $3.01 \times 10^{-3}$ & 6.75 & 8.36 & 3.06 \\
MEGF10 & $8.38 \times 10^{-7}$ & 7.37 & 4.70 & 0.16 \\
SYNPR & $1.25 \times 10^{-5}$ & 9.15 & 6.83 & 0.20 \\
CHL1 & $8.99 \times 10^{-8}$ & 6.34 & 4.10 & 0.21 \\
OVOS2 & $2.44 \times 10^{-7}$ & 9.74 & 7.54 & 0.22 \\
LOC100128252 & $5.70 \times 10^{-6}$ & 7.54 & 5.55 & 0.25 \\
MPPED2 & $5.58 \times 10^{-6}$ & 6.28 & 4.40 & 0.27 \\
CNTN3 & $1.37 \times 10^{-5}$ & 5.40 & 3.60 & 0.29 \\
PCDH20 & $2.94 \times 10^{-3}$ & 5.82 & 4.07 & 0.30 \\
\hline
\end{tabular}

Most obviously dysregulated genes with fold change absolute value $>3$ in liver metastatic uveal melanoma $(n=45)$ vs. non-metastatic tumors $(n=46)$. 
Table 4 Different gene significant upregulated GO

GO item
Germ cell programmed cell death
Developmental programmed cell death
Protein retention in ER lumen
Germ cell migration
Melanocyte differentiation
Mitotic cell cycle spindle assembly
checkpoint
Negative regulation of mitotic metaphase/
anaphase transition

Pigmentation during development

Pigment cell differentiation

Antigen processing and presentation of peptide antigen via MHC class I

Positive regulation of calcium ion transport into cytosol

Regulation of calcium ion transport into cytosol

T cell proliferation

Regulation of transforming growth factor beta receptor signaling pathway

Positive regulation of homeostatic process Fold enrichment

$\begin{array}{ll}32.29 & 2.80 \times 10^{-3} \\ 19.37 & 8.95 \times 10^{-3} \\ 13.84 & 1.80 \times 10^{-2} \\ 13.45 & 3.65 \times 10^{-4} \\ 9.22 & 8.27 \times 10^{-3} \\ 8.81 & 4.36 \times 10^{-2}\end{array}$

Response to vitamin A

Pigmentation

Mitotic cell cycle checkpoint

Regulation of calcium ion transport

Extracellular matrix organization

Alcohol biosynthetic process

Regulation of metal ion transport

Leukocyte mediated immunity

Cellular response to insulin stimulus

Regulation of ion transport

Lymphocyte mediated immunity

Response to organic cyclic substance

Response to toxin

Double-strand break repair

Sphingolipid metabolic process

Response to molecule of bacterial origin

Adaptive immune response

Response to lipopolysaccharide

Adaptive immune response based on somatic recombination of immune receptors built from immunoglobulin superfamily domains

Cellular response to hormone stimulus

Response to insulin stimulus

Membrane lipid metabolic process

Activation of MAPK activity
$P$ value

$4.36 \times 10^{-2}$

$4.36 \times 10^{-2}$

$1.14 \times 10^{-4}$

$1.01 \times 10^{-2}$

$1.44 \times 10^{-2}$

7.60

6.46

5.57

4.78

4.14

4.04

$2.26 \times 10^{-2}$

$1.16 \times 10^{-2}$

$4.95 \times 10^{-2}$

$3.15 \times 10^{-2}$

$3.42 \times 10^{-2}$

$4.00 \times 10^{-2}$

$9.50 \times 10^{-3}$

$4.30 \times 10^{-2}$

$5.31 \times 10^{-3}$

$3.63 \times 10^{-4}$

$4.62 \times 10^{-2}$

$3.49 \times 10^{-3}$

$5.04 \times 10^{-3}$

$1.83 \times 10^{-2}$

$3.51 \times 10^{-3}$

$2.09 \times 10^{-2}$

$1.30 \times 10^{-3}$

$3.98 \times 10^{-2}$

$4.23 \times 10^{-2}$

$2.82 \times 10^{-2}$

$1.70 \times 10^{-2}$

$3.16 \times 10^{-2}$

$3.16 \times 10^{-2}$

$3.16 \times 10^{-2}$

$2.77 \times 10^{-3}$

$1.22 \times 10^{-2}$

$3.91 \times 10^{-2}$

$4.11 \times 10^{-2}$
Table 4 Different gene significant upregulated GO (Continued)

Immune effector process 2.65

Protein processing

2.59

Extracellular structure organization

2.57

Response to oxidative stress

2.56

Positive regulation of MAP kinase activity

2.53

Regulation of MAP kinase activity

Amine transport

Camera-type eye development

Carbohydrate biosynthetic process

Protein oligomerization

Protein maturation

Nucleotide biosynthetic process

Nucleobase, nucleoside and

nucleotide biosynthetic process

Nucleobase, nucleoside, nucleotide

and nucleic acid biosynthetic process

Cell proliferation

Muscle organ development

Regulation of neurogenesis

Skeletal system development

Response to peptide hormone stimulus

Transmembrane receptor protein tyrosine kinase signaling pathway

Regulation of nervous

system development

Nitrogen compound

biosynthetic process

Enzyme linked receptor protein signaling pathway

Response to drug

Blood vessel development

Response to DNA damage stimulus

Induction of apoptosis

Induction of programmed cell death

Positive regulation of apoptosis

2.52

2.46

2.41

2.41

2.41

2.38

2.26

2.17

2.17

2.15

2.14

2.14

2.13

2.10

2.02

2.02

1.99

1.98

1.94

1.84

1.82

1.82

1.81

1.80

Vasculature development

Positive regulation of programmed cell death 1.79

Positive regulation of cell death

1.78

$M$ phase

Response to hormone stimulus

Response to endogenous stimulus

Cell cycle phase

Response to abiotic stimulus
Protein kinase cascade

Cellular response to stress

Response to organic substance
$8.66 \times 10^{-3}$

$2.27 \times 10^{-2}$

$4.72 \times 10^{-3}$

$4.95 \times 10^{-3}$

$3.86 \times 10^{-2}$

$1.21 \times 102$

$2.99 \times 10^{-2}$

$4.79 \times 10^{-2}$

$4.79 \times 10^{-2}$

$7.85 \times 10^{-3}$

$3.54 \times 10^{-2}$

$1.29 \times 102$

$1.69 \times 10^{-2}$

$1.69 \times 10^{-2}$

$2.12 \times 10^{-4}$

$1.41 \times 102$

$3.34 \times 10^{-2}$

$2.21 \times 10^{-3}$

$4.96 \times 10^{-2}$

$2.20 \times 10^{-2}$

$3.63 \times 10^{-2}$

$5.98 \times 10^{-3}$

$4.86 \times 10^{-3}$

$3.62 \times 10^{-2}$

$4.11 \times 10^{-2}$

$1.20 \times 10^{-2}$

$2.14 \times 10^{-2}$

$2.19 \times 10^{-2}$

$7.74 \times 10^{-3}$

$4.83 \times 10^{-2}$

$8.09 \times 10^{-3}$

$8.74 \times 10^{-3}$

$2.70 \times 10^{-2}$

$1.98 \times 10^{-2}$

$1.46 \times 10^{-2}$

$1.82 \times 10^{-2}$

$3.73 \times 10^{-2}$

$3.89 \times 10^{-2}$

$9.67 \times 10^{-3}$

$5.45 \times 10^{-3}$ 
Table 4 Different gene significant upregulated GO (Continued)

\begin{tabular}{lll}
\hline Phosphorylation & 1.57 & $5.41 \times 10^{-3}$ \\
Oxidation reduction & 1.57 & $1.51 \times 10^{-2}$ \\
Phosphate metabolic process & 1.56 & $2.49 \times 10^{-3}$ \\
Phosphorus metabolic process & 1.56 & $2.49 \times 10^{-3}$ \\
Cell cycle process & 1.54 & $2.79 \times 10^{-2}$ \\
Protein amino acid phosphorylation & 1.50 & $2.49 \times 10^{-2}$ \\
Immune response & 1.50 & $2.35 \times 10^{-2}$ \\
Regulation of cell proliferation & 1.44 & $3.02 \times 10^{-2}$ \\
Regulation of programmed cell death & 1.43 & $2.88 \times 10^{-2}$ \\
Regulation of cell death & 1.43 & $3.01 \times 10^{-2}$ \\
Regulation of apoptosis & 1.41 & $3.91 \times 10^{-2}$ \\
\hline
\end{tabular}

on patients' age, gender or tumor diameter. The tumor thickness value was much larger in the liver metastases samples than in the non-metastases group. Though the tumor location, extrascleral extension, tumor cell type and chromosome 3 data were incomplete, the first two appeared no differences while the mixed subtype tumor and chromosome 3 monosomy showed positive correlation with liver metastases of uveal melanoma (Table 1).

\section{Liver metastases-related differential expression genes}

Using liver metastases as the demarcation, genes of nonmetastases and liver metastases groups were compared and 1138 statistically significant differential expression probes were obtained. Of them, 768 probes were upregulated in the non-metastases samples and 370 were down-regulated. Hierarchical clustering showed systematic variations in the expression of genes between the two groups (Figure 1). The results demonstrated these differential probes could clearly separate the two groups from the whole samples and have good consistency in the group. Different genes with the most obvious $\mathrm{p}$ value and fold change between the liver metastases and nonmetastases group were listed (Tables 2 and 3).

\section{Significant GOs}

GOs of the differential expression genes were statistically analyzed. It was found that the differential expression genes obtained from the Microarray mainly participated in 125 significant GOs. According to the enrichment list, the up-regulated differential expression genes mainly participated in 89 GOs including germ cell programmed cell death, developmental programmed cell death, germ cell migration, melanocyte differentiation (Table 4), and the down-regulated differential expression genes mainly participated in 36 GOs including embryonic skeletal system development, regulation of Rho protein signal transduction, regulation of cell morphogenesis (Table 5).

\section{Significant Pathways}

The pathways of liver metastatic uveal melanoma samples were analyzed according to the functions and interactions of the differential genes. By using Pathway-Express which contains both the up- and down- regulated differential genes in its analysis and the threshold of significance

Table 5 Different gene significant downregulated GO

\begin{tabular}{|c|c|c|}
\hline GO item & $\begin{array}{l}\text { Fold } \\
\text { enrichment }\end{array}$ & $P$ value \\
\hline Calcium-dependent cell-cell adhesion & 9.49 & $3.90 \times 10^{-2}$ \\
\hline Response to acid & 9.09 & $4.22 \times 10^{-2}$ \\
\hline Embryonic skeletal system development & 5.67 & $4.04 \times 10^{-3}$ \\
\hline Response to vitamin & 5.51 & $1.26 \times 10^{-2}$ \\
\hline Regulation of cell shape & 5.39 & $3.75 \times 10^{-2}$ \\
\hline $\begin{array}{l}\text { Regulation of Rho protein signal } \\
\text { transduction }\end{array}$ & 5.14 & $2.36 \times 10^{-3}$ \\
\hline Pigmentation & 4.93 & $4.68 \times 10^{-2}$ \\
\hline Cartilage development & 4.91 & $1.85 \times 10^{-2}$ \\
\hline Skeletal system morphogenesis & 3.90 & $1.88 \times 10^{-2}$ \\
\hline Regulation of cell morphogenesis & 3.89 & $9.22 \times 10^{-3}$ \\
\hline Translational elongation & 3.60 & $4.97 \times 10^{-2}$ \\
\hline Muscle tissue development & 3.49 & $2.85 \times 10^{-2}$ \\
\hline Homophilic cell adhesion & 3.33 & $3.40 \times 10^{-2}$ \\
\hline Regulation of neuron differentiation & 3.28 & $3.59 \times 10^{-2}$ \\
\hline Embryonic organ morphogenesis & 3.28 & $3.59 \times 10^{-2}$ \\
\hline Regulation of cell development & 3.19 & $7.23 \times 10^{-3}$ \\
\hline Regulation of Ras protein signal transduction & 3.12 & $8.25 \times 10^{-3}$ \\
\hline Muscle organ development & 3.10 & $8.54 \times 10^{-3}$ \\
\hline Regulation of neurogenesis & 3.07 & $2.66 \times 10^{-2}$ \\
\hline Response to drug & 3.03 & $9.75 \times 10^{-3}$ \\
\hline Embryonic organ development & 2.96 & $3.09 \times 10^{-2}$ \\
\hline $\begin{array}{l}\text { Regulation of small GTPase mediated signal } \\
\text { transduction }\end{array}$ & 2.89 & $7.88 \times 10^{-3}$ \\
\hline Skeletal system development & 2.74 & $4.38 \times 10^{-3}$ \\
\hline Heart development & 2.71 & $2.85 \times 10^{-2}$ \\
\hline Regulation of nervous system development & 2.65 & $4.85 \times 10^{-2}$ \\
\hline Cell-cell adhesion & 2.64 & $1.37 \times 10^{-2}$ \\
\hline Negative regulation of cell proliferation & 2.62 & $4.07 \times 10^{-3}$ \\
\hline Cell adhesion & 2.60 & $2.99 \times 10^{-5}$ \\
\hline Biological adhesion & 2.59 & $3.06 \times 10^{-5}$ \\
\hline Actin cytoskeleton organization & 2.57 & $3.59 \times 10^{-2}$ \\
\hline Actin filament-based process & 2.41 & $4.79 \times 10^{-2}$ \\
\hline Chordate embryonic development & 2.20 & $3.87 \times 10^{-2}$ \\
\hline $\begin{array}{l}\text { Embryonic development ending in birth or } \\
\text { egg hatching }\end{array}$ & 2.18 & $4.03 \times 10^{-2}$ \\
\hline Cytoskeleton organization & 2.17 & $1.68 \times 10^{-2}$ \\
\hline Regulation of cell proliferation & 2.03 & $2.54 \times 10^{-3}$ \\
\hline Response to organic substance & 1.71 & $3.85 \times 10^{-2}$ \\
\hline
\end{tabular}


defined on the basis of gamma P-value $<0.05,16$ significant pathways were found. Many signaling pathways had been verified to relate to cell migration and invasion, including Phosphatidylinositol signaling system, Gap junction, Adherens junction (Figure 2).

\section{Signal-network}

According to the literature and experimental records in the databases, a diagram of the gene interaction network was drawn up based on the genes differentially expressed between liver metastases and non-metastases uveal melanoma (Figure 3). The total number of genes in the network was 297, and the particular relationships between them were listed (Additional file 3). In the network, cycle nodes represent genes, and edges between two nodes represent interactions between genes, which were quantified by degree. Degrees within the network which describe the number of single gene that regulates other genes represent the size of the cycle node. The higher the degree, the more central the gene occurs within the network. There were many more genes upregulated involved in the Signal-Net analysis, of which YWHAZ, PRKDC, and ESR1 were the three main overexpressed genes, while the three main underexpressed genes were FYN, TIAM1 and GNAI1.

\section{Discussion}

The present study followed up microarray-based 91 uveal melanoma patients, of whom patients were not significantly different in age, gender and tumor diameter. More than 1100 probes were differentially dysregulated in liver metastases uveal melanoma in this study. Based on sorting the different genes by $\mathrm{p}$ value and fold change, numbers of genes with the largest difference individually were carried out. HTR2B is a type of serotonin receptor with both the extremely significant $\mathrm{p}$ value and the largest upregulated fold change in the two groups.

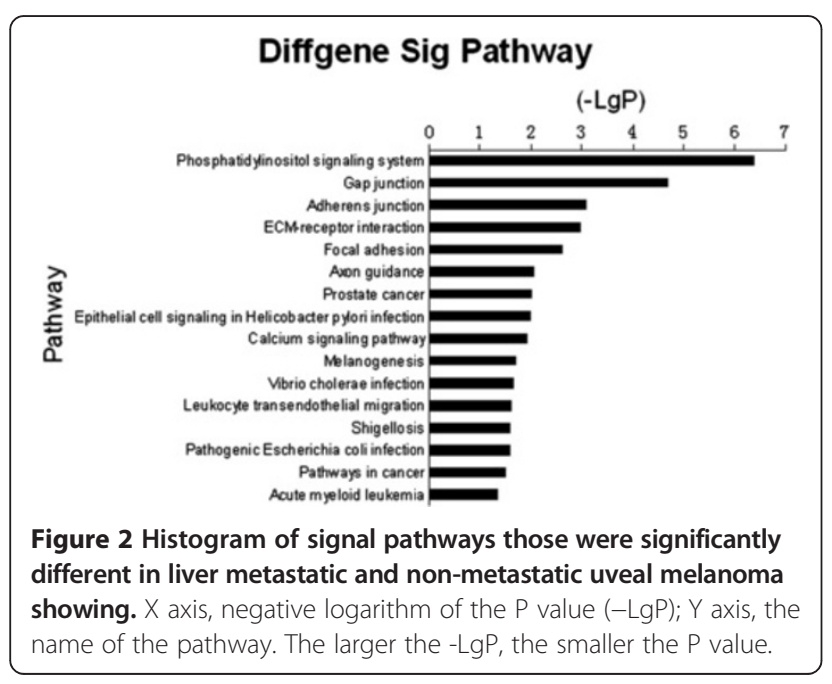

Soll et al. had found serotonin can promote tumor growth in hepatocellular cancer [24] and this maybe an effective hint to us. CHL1 is a cell adhesion molecule with homology to L1CAM involved in the regulation of cell adhesion and migration. Current study had supported a significant role for CHL1 gene in the growth, migration and invasion of human cervical cancer cells [25]. MEGF10 and OVOS2 have the largest downregulated fold change and a significant $\mathrm{p}$ value. It is still lack of information about their roles both in tumor and ophthalmology. Zinc finger proteins are among the most abundant proteins which were involved in transcriptional activation, apoptosis regulation and protein folding. Some zinc finger protein had been detected related to melanoma [26]. However, there have been no reports of a differential expression of ZNF family members in liver metastases uveal melanoma. Comparing with the original papers of the expression microarray, we found PTP4A3/PRL3 still has significant difference while SDCBP dropped out with too little fold change. In our opinion, this is caused by the enlargement of sample number which may impact larger in the previously smaller sample group for GSE27831 has only 29 samples. For the sample number we integrate here is not so small, though these genes were still lack of information about their impact on uveal melanoma liver metastases, we have the reason to focus on them in further investigation.

The GO is widely recognized as the premier tool for the organization and functional annotation of molecular aspect [27]. GO-analysis was used to interpret each GO of differential expressed gene and analyzed it statistically. By using the criteria of $\mathrm{P}<0.05$, we obtained the significant GOs and genes involved in them. Guo et al. used GO-analysis to analyze miRNA microarray and found that miR-15b and miR-16 may be indispensable for apoptosis by targeting Bcl-2 [28]. GO terms about programmed cell death plays an important role in liver metastases, many studies had reported proteins such as TRAIL and TGF- $\beta 1$ involved in cell apoptosis also affected cancer cell metastases $[29,30]$. Ion transport related genes is little investigated in cancer cell metastases, but recently Lee et al. found monoamine carboxylate transporters could impact colon fibrosarcoma cell migration through regulating extracellular $\mathrm{pH}$ value [31]. This may be a new way investigating uveal melanoma liver metastases. Also the structural changes of intracellular organelles and cytoskeletal would of course act on cell migration and invasion. According to our results, programmed cell death, ion transport and cytoskeletal would affect cell environment to play roles in liver metastases. Furthermore, other biological process may also have their effects in uveal melanoma distant metastases.

Pathways analysis can show the distinct biological process and find significant pathways that differential 


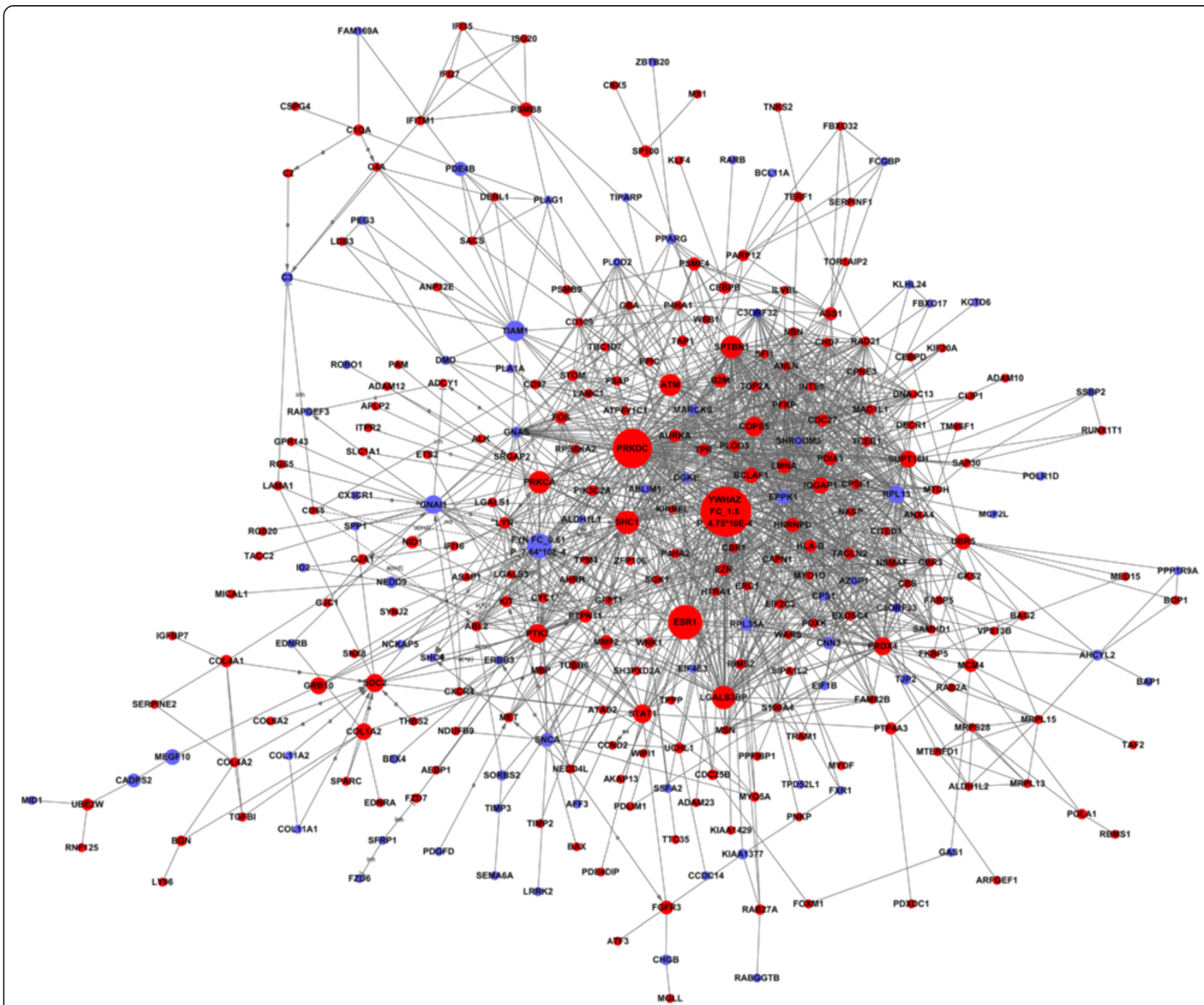

Figure 3 Signal transduction networks of liver metastatic related genes. Circle represents genes, red circle represents the upregulated gene, and blue circle represents the downregulated gene. Arrow represents the activation of (a); straight line represents combine; dotted line represents indirect effects; a represents activation; ex represents gene expression; b represents binding; ind represents indirect effects; inh represents inhibition; $\mathrm{u}$ represents ubiquination. For the most interesting nodes, the fold change and $\mathrm{p}$ value were added to the YWHAC and FYN.

expression genes participate in, based on which can we have a comprehensive understanding about interactions of genes, functions that they participate in and relations between up- and down-stream, and obtain genes involved in these significant pathways. Appearance of pathways about cell junction, melanogenesis and calcium signaling pathway confirm their concordance with GO terms and their critical role in liver metastases. Numerous studies had proved PI3K/Akt signaling pathway which belongs to phosphatidylinositol signaling pathway participated in different cancers' liver metastases [32-34]. Holder et al. had reported gap junction may affect cancer metastases since connections are made between the primary tumor cells and foreign host cells at the secondary metastatic site [35]. Found of epimorphin activating focal adhesion kinase/extracellular signal-regulated kinase/matrix metalloproteinase- 9 axis to promote hepatocellular carcinoma invasion and metastases verified focal adhesion and ECM-receptor interaction's role in liver metastases. For this, we have reasons to believe the other seemingly irrelevant pathways would have their functions in uveal melanoma metastases.

Investigating genes involved in significant GOs and pathways, 297 genes in common were found that may affect the liver metastases of uveal melanoma patients. YWHAZ and FYN were identified as key genes in uveal melanoma liver metastases and play crucial roles in cell proliferation, which may be related to the higher incidence of metastases in uveal melanoma. YWHAZ previously was thought as a reference gene in many cell lines, 
recently it was found to play a major role in YWHAZ/ beta-Catenin Axis and promote Epithelial-Mesenchymal Transition and Lung Cancer Metastases [36,37]. FYN was a member of the Src family of kinases and though lack of data about its role in uveal melanoma, it participated in many cancers metastases through different pathways [38-40]. Based on these data, further studies of these genes' expression and the protein functions of HTR2B, CHL1, the ZNF family, YWHAZ and FYN need to be performed in more samples using reverse transcriptase-polymerase chain reaction and western blotting; moreover, for the GO and pathway findings are based on the currently known database, the regulation of identified genes and protein functions may have some other ways.

The above results all suggest that differences in gene expression exist between liver metastases and non liver metastases uveal melanoma. These genes encode proteins involved in different GOs and signal pathways, the disruption of which can promote cancer metastases. Several genes, such as HTR2B, CHL1, the ZNF family, YWHAZ and FYN provide potential candidates for distinguishing between uveal melanoma whether contain liver metastases in the future. This distinction will aid in the diagnosis and prevention of uveal melanoma liver metastases, based on their different features. Therefore, our results may provide important referential merit for clinical investigation. Nevertheless, the genes and the related GOs and pathways identified here are required to be further dissected and confirmed in more patient samples by other clinic-related studies.

\section{Conclusion}

Bioinformatics may help excavate and analyze large amounts of data in microarrays by means of rigorous experimental planning, scientific statistical analysis and collection of complete data about liver metastases of uveal melanoma patients. In the present study, a novel differential gene expression pattern was constructed and advanced study will provide new targets for diagnosis and mechanism of uveal melanoma liver metastases.

\section{Additional files}

Additional file 1: Figure S1. Normalized microarray data by Pearson's Correlation. Uveal melanoma samples microarray data were normalized by Pearson's Correlation and one sample GSM685470 was removed.

Additional file 2: Figure S2. Venn diagram for different methods of gene expression analysis. T-test, SAM and RVM mode were used to screen the differential expressed genes.

Additional file 3: Gene feature and relationship in the liver metastatic related signal transduction network.

\section{Competing interests}

The authors declare that they have no competing interests.

\section{Authors' contributions}

YZ carried out the molecular genetic studies, participated in the gene alignment and drafted the manuscript. YY participated in the design of the study and performed the statistical analysis. LC participated in the gene alignment and its design and coordination. JZ conceived of the study, and participated in its design and coordination. All authors read and approved the final manuscript.

\section{Acknowledgements}

This study was supported by the 11th five-year plan of science and technology research projects of China (no. 2007BAl18B07).

\section{Author details}

'Department of Ophthalmology, The branch of the first people's hospital of Shanghai, Shanghai 200081, China. ${ }^{2}$ Department of Thoracic Surgery, Shanghai Pulmonary Hospital, Shanghai 200433, China. ${ }^{3}$ Department of Ophthalmology, The First Hospital of China Medical University, Shenyang 110001, China.

Received: 29 December 2012 Accepted: 12 February 2014

Published: 5 March 2014

\section{References}

1. Shields JA, Shields CL, De Potter P, Singh AD: Diagnosis and treatment of uveal melanoma. Semin Oncol 1996, 23(6):763-767.

2. Sibbritt T, Patel HR, Preiss T: Mapping and significance of the mRNA methylome. Wiley Interdiscip Rev RNA 2013, 4(4):397-422.

3. Trolet J, Hupe P, Huon I, Lebigot I, Decraene C, Delattre O, Sastre-Garau X, Saule S, Thiery JP, Plancher C, Asselain B, Desjardins L, Mariani P, PipernoNeumann S, Barillot E, Couturier J: Genomic profiling and identification of high-risk uveal melanoma by array CGH analysis of primary tumors and liver metastases. Invest Ophthalmol Vis Sci 2009, 50(6):2572-2580.

4. Augsburger JJ, Correa ZM, Shaikh AH: Effectiveness of treatments for metastatic uveal melanoma. Am J Ophthalmol 2009, 148(1):119-127.

5. Onken MD, Worley LA, Ehlers JP, Harbour JW: Gene expression profiling in uveal melanoma reveals two molecular classes and predicts metastatic death. Cancer Res 2004, 64(20):7205-7209.

6. Onken MD, Ehlers JP, Worley LA, Makita J, Yokota Y, Harbour JW: Functional gene expression analysis uncovers phenotypic switch in aggressive uveal melanomas. Cancer Res 2006, 66(9):4602-4609.

7. Petrausch $U$, Martus P, Tonnies H, Bechrakis NE, Lenze D, Wansel S, Hummel M, Bornfeld N, Thiel E, Foerster MH, Keilholz U: Significance of gene expression analysis in uveal melanoma in comparison to standard risk factors for risk assessment of subsequent metastases. Eye (Lond) 2008, 22(8):997-1007.

8. Mallikarjuna K, Pushparaj V, Biswas J, Krishnakumar S: Expression of epidermal growth factor receptor, ezrin, hepatocyte growth factor, and c-Met in uveal melanoma: an immunohistochemical study. Curr Eye Res 2007, 32(3):281-290.

9. Di Cesare S, Marshall JC, Logan P, Antecka E, Faingold D, Maloney SC, Burnier MN Jr: Expression and migratory analysis of 5 human uveal melanoma cell lines for CXCL12, CXCL8, CXCL1, and HGF. J Carcinog 2007, 6:2.

10. Peruzzi B, Bottaro DP: Targeting the c-met signaling pathway in cancer. Clin Cancer Res 2006, 12(12):3657-3660.

11. All-Ericsson C, Girnita L, Seregard S, Bartolazzi A, Jager MJ, Larsson O: Insulin-like growth factor-1 receptor in uveal melanoma: a predictor for metastatic disease and a potential therapeutic target. Invest Ophthalmol Vis Sci 2002, 43(1):1-8.

12. Mouriaux F, Kherrouche Z, Maurage CA, Demailly FX, Labalette P, Saule S: Expression of the c-kit receptor in choroidal melanomas. Melanoma Res 2003, 13(2):161-166

13. Mouriaux F, Chahud F, Maurage CA, Malecaze F, Labalette P: Implication of stem cell factor in the proliferation of choroidal melanocytes. Exp Eye Res 2001, 73(2):151-157.

14. Lefevre G, Glotin AL, Calipel A, Mouriaux F, Tran T, Kherrouche Z, Maurage CA Auclair C, Mascarelli F: Roles of stem cell factor/c-Kit and effects of Glivec/STI571 in human uveal melanoma cell tumorigenesis. J Biol Chem 2004, 279(30):31769-31779.

15. Scala S, lerano C, Ottaiano A, Franco R, La Mura A, Liguori G, Mascolo M, Staibano S, Ascierto PA, Botti G, De Rosa G, Castello G: CXC chemokine receptor 4 is expressed in uveal malignant melanoma and correlates 
with the epithelioid-mixed cell type. Cancer Immunol Immunother 2007, 56(10):1589-1595.

16. Franco R, Botti G, Mascolo M, Loquercio G, Liguori G, llardi G, Losito $S$, La Mura A, Calemma R, lerano C, Bryce J, D'Alterio C, Scala S: CXCR4CXCL12 and VEGF correlate to uveal melanoma progression. Front BiosCi (Elite Ed) 2010, 2:13-21.

17. Gangemi R, Mirisola V, Barisione G, Fabbi M, Brizzolara A, Lanza F, Mosci C, Salvi S, Gualco M, Truini M, Angelini G, Boccardo S, Cilli M, Airoldi I, Queirolo P, Jager MJ, Daga A, Pfeffer U, Ferrini S: Mda-9/syntenin is expressed in uveal melanoma and correlates with metastatic progression. Plos One 2012, 7(1):e29989.

18. Laurent $C$, Valet F, Planque $N$, Silveri L, Maacha $S$, Anezo O, Hupe $P$, Plancher C, Reyes C, Albaud B, Rapinat A, Gentien D, Couturier J, SastreGarau X, Desjardins L, Thiery JP, Roman-Roman S, Asselain B, Barillot E, Piperno-Neumann S, Saule S: High PTP4A3 phosphatase expression correlates with metastatic risk in uveal melanoma patients. Cancer Res 2011, 71(3):666-674.

19. Jeanmougin M, de Reynies A, Marisa L, Paccard C, Nuel G, Guedj M: Should we abandon the $t$-test in the analysis of gene expression microarray data: a comparison of variance modeling strategies. Plos One 2010, 5(9):e12336.

20. Eisen MB, Spellman PT, Brown PO, Botstein D: Cluster analysis and display of genome-wide expression patterns. Proc Natl Acad Sci U S A 1998, 95(25):14863-14868.

21. Dennis G Jr, Sherman BT, Hosack DA, Yang J, Gao W, Lane HC, Lempicki RA: DAVID: database for annotation, visualization, and integrated discovery. Genome Biol 2003, 4(5):3.

22. Khatri P, Draghici S, Ostermeier GC, Krawetz SA: Profiling gene expression using onto-express. Genomics 2002, 79(2):266-270.

23. Draghici S, Khatri P, Martins RP, Ostermeier GC, Krawetz SA: Global functional profiling of gene expression. Genomics 2003, 81(2):98-104

24. Soll C, Jang JH, Riener MO, Moritz W, Wild PJ, Graf R, Clavien PA: Serotonin promotes tumor growth in human hepatocellular cancer. Hepatology 2010, 51(4):1244-1254.

25. Long MJ, Wu FX, Li P, Liu M, Li X, Tang H: MicroRNA-10a targets CHL1 and promotes cell growth, migration and invasion in human cervical cancer cells. Cancer Lett 2012, 324(2):186-196.

26. Yajima I, Kumasaka M, Thang ND, Yanagishita T, Ohgami N, Kallenberg D, Naito Y, Yoshikawa T, Sakashita N, Kato M: Zinc finger protein 28 as a novel melanoma-related molecule. J Dermatol Sci 2009, 55(1):68-70.

27. Lovering RC, Camon EB, Blake JA, Diehl AD: Access to immunology through the gene ontology. Immunology 2008, 125(2):154-160.

28. Guo CJ, Pan Q, Li DG, Sun H, Liu BW: miR-15b and miR-16 are implicated in activation of the rat hepatic stellate cell: an essential role for apoptosis. J Hepatol 2009, 50(4):766-778.

29. Yu SC, Leung TW, Lee KT, Wong LK: Angioplasty and stenting of intracranial atherosclerosis with the wingspan system: 1-year clinical and radiological outcome in a single Asian center. J Neurointerv Surg 2014, 6:96-102.

30. Armstrong SR, Campbell CB, Richardson CL, Vickery RG, Tsuruda PR, Long DD, Hegde SS, Beattie DT: The in vivo pharmacodynamics of the novel opioid receptor antagonist, TD-1211, in models of opioid-induced gastrointestinal and CNS activity. Naunyn Schmiedebergs Arch Pharmacol 2013, 386(6):471-478.

31. Festa F, Steel J, Bian X, Labaer J: High-throughput cloning and expression library creation for functional proteomics. Proteomics 2013, 13(9):1381-1399.

32. Lublin FD: MS as a gateway disease. I Neurol Sci 2013, 333(1-2):73-75

33. Grana RA: Electronic cigarettes: a new nicotine gateway? J Adolesc Health 2013, 52(2):135-136.

34. Shukla S, Chandran S, Gadagkar R: Ovarian developmental variation in the primitively eusocial wasp ropalidia marginata suggests a gateway to worker ontogeny and the evolution of sociality. J Exp Biol 2013, 216(Pt 2):181-187.

35. Mueller MB, Blunk T, Appel B, Maschke A, Goepferich A, Zellner J, Englert C, Prantl L, Kujat R, Nerlich M, Angele P: Insulin is essential for in vitro chondrogenesis of mesenchymal progenitor cells and influences chondrogenesis in a dose-dependent manner. Int Orthop 2013, 37(1):153-158

36. Chen CH, Chuang SM, Yang MF, Liao JW, Yu SL, Chen JJ: A novel function of YWHAZ/beta-catenin axis in promoting epithelial-mesenchymal transition and lung cancer metastasis. Mol Cancer Res 2012, 10(10):1319-1331.
37. Chua SL, See Too WC, Khoo BY, Few LL: UBC and YWHAZ as suitable reference genes for accurate normalisation of gene expression using MCF7, HCT116 and HepG2 cell lines. Cytotechnology 2011, 63(6):645-654.

38. Wang Q, Qian J, Wang F, Ma Z: Cellular prion protein accelerates colorectal cancer metastasis via the Fyn-SP1-SATB1 axis. Oncol Rep 2012, 28(6):2029-2034.

39. Yadav V, Denning MF: Fyn is induced by Ras/PI3K/Akt signaling and is required for enhanced invasion/migration. Mol Carcinog 2011, 50(5):346-352.

40. Kim AN, Jeon WK, Lim KH, Lee HY, Kim WJ, Kim BC: Fyn mediates transforming growth factor-beta1-induced down-regulation of E-cadherin in human A549 lung cancer cells. Biochem Biophys Res Commun 2011, 407(1):181-184.

doi:10.1186/1471-2350-15-29

Cite this article as: Zhang et al:: Expression analysis of genes and pathways associated with liver metastases of the uveal melanoma. BMC Medical Genetics 2014 15:29.

\section{Submit your next manuscript to BioMed Central and take full advantage of:}

- Convenient online submission

- Thorough peer review

- No space constraints or color figure charges

- Immediate publication on acceptance

- Inclusion in PubMed, CAS, Scopus and Google Scholar

- Research which is freely available for redistribution 